Available online at GSC Online Press Directory

GSC Biological and Pharmaceutical Sciences

e-ISSN: 2581-3250, CODEN (USA): GBPSC2

Journal homepage: https://www.gsconlinepress.com/journals/gscbps

(RESEARCH ARTIClE)

\title{
Phytochmical analysis and antibacterial property assessment of helencha (Enhydra fluctuans; Family: Asteraceae) extracts
}

\author{
Sima Sikdar ${ }^{1}$, Surajit Roy ${ }^{1}$, Tarique Nazira Banu ${ }^{1}$, Mohabul Alam Mondal ${ }^{2}$ and Shyamapada Mandal 1,* \\ ${ }^{1}$ Laboratory of Microbiology and Experimental Medicine, Department of Zoology, University of Gour Banga, Malda- \\ 732103, India \\ 2 Department of Chemistry, Jadavpur University, Raja SC Mallick Road, Jadavpur, Kolkata-700032, India.
}

Publication history: Received on 04 August 2020; revised on 14 August 2020; accepted on 15 August 2020

Article DOI: https://doi.org/10.30574/gscbps.2020.12.2.0252

\begin{abstract}
This communication stands for the phytochemical analysis, and antibacterial activity of Enhydra fluctuans, alone and in combination with some antibiotics, against gram-negative and gram-positive bacteria. Following disc diffusion, the methanolic extract of E. fluctuans (MEE) had antibacterial activity against gram-positive (B. cereus and $L$. monocytogenes) and gram-negative (A. baumannii and P. aeruginosa) clinical as well as standard (E. coli ATCC 25922 and L. monocytogenes MTCC 657) bacterial strains, displaying ZDI (zone of the diameter of inhibition) values $12-24$ $\mathrm{mm}$. The aqueous extract of $E$. fluctuans (AEE) showed no activity against $P$. aeruginosa; however, for the other test bacterial isolates AEE had ZDIs of 13 - $21 \mathrm{~mm}$ (for gram-negative bacteria) and 10 - $17 \mathrm{~mm}$ (for gram-positive bacteria). The MIC (minimum inhibitory concentration) values of MEE, for both gram-negative and gram-positive bacteria, ranged from 2.5 to $10 \mathrm{mg} / \mathrm{ml}$, by agar dilution method. The extracts (AEE and MEE) were screened qualitatively to contain bioactive components: flavonoids, glycosides, steroids, terpenoids, phenols, quinone and saponins, while cardiac glycoside was detected in AEE only. The HPLC chromatogram showed the presence of 14 detectable compounds, within the retention time of $1.53-5.69 \mathrm{~min}$, in MEE. The growth inhibitory indices of $0.59-1.08$, from the antibiotic-MEE combined action, demonstrated synergism against the test bacterial strains. The $E$. fluctuans, alone or in combination with antibiotics, might be useful in combating infections caused by both gram-negative and gram-positive bacteria.
\end{abstract}

Keywords: Pathogenic bacteria; Enhydra fluctuans; Antibacterial activity; Synergism; Phytochemicals.

\section{Introduction}

Antibiotics are essentially in use in the clinical medicine to reduce the global burden of many of the life-threatening diseases of bacterial infections to humans. However, prolonged use of antibiotics available in the market and their mishandling led to the emergence of antibiotic resistant pathogenic bacteria (ARPB): MDR (multidrug resistant), XDR (extensively drug resistant) and PDR (pan-drug resistant) [1], and their rapid dissemination as well, around the globe. Fighting against the ARPB infections, it is of overriding importance to find new effective antimicrobial agents, mainly the biotherapeutics, from different biological sources including the medicinal plants. The World Health Organization (WHO) considered the (medicinal) plants as the vital source of an array of bioactive components to be used in combating bacterial antibiotic resistances [2]. India holds the capacity of growing enormous number of plants, which have been in use for the remedies of different kinds of human illnesses since ancient. Currently, scientific studies have proved the presence, in different medicinal food plants, of an ample of varieties of 'secondary metabolites' (phenolics, tannins, alkaloids and flavonoids, etc.) possessing antimicrobial properties [3].

\footnotetext{
* Corresponding author: Shyamapada Mandal

Laboratory of Microbiology and Experimental Medicine, Department of Zoology, University of Gour Banga, Malda-732103, India
} 
It has been reported that the plant, Enhydra fluctuans displayed antioxidant, hepatoprotective, anti-depressant, analgesic and anti-diarrheal activities, and had antibacterial activity against Escherichia coli, Pseudomonas aeruginosa, Staphylococcus aureus and Micrococcus luteus [4]. Akhe et al. [5] developed an HPLC method to analyze and identify the bioactive compounds in E. fluctuans displaying antibacterial activity. However, no scientific report is available on the issues of bioactive phytochemicals and antibacterial potentialities of E. fluctuans from our part of the globe.

The above background prompted us to the analysis of phytochemical components and antibacterial activity of a native of India vegetable plant, E. fluctuans (known as helencha in Bengali), which grow naturally and enormously in semi aquatic environments of various parts of West Bengal state, India, and are easily available for consumption. Therefore, the current study aims to authenticate the presence of bioactive components in E. fluctuans, from local niches (Malda, India), and the antibacterial activity of the plant, as well.

\section{Material and methods}

\subsection{Bacterial strains}

The clinical bacterial isolates: gram-negative (Acinetobacter baumannii and Pseudomonas aeruginosa) and grampositive (Bacillus cereus and Listeria monocytogenes), and the standard strains of bacteria: Escherichia coli ATCC25922 and Listeria monocytogenes MTCC657 were utilized in the study. The bacteria were maintained in the laboratory in cystine tryptone agar stabs, at room temperature.

\subsection{Plant materials and extract preparation}

The whole aerial parts (stem and leaves) of Enhydra fluctuans (Bengali name Helencha) were collected from local market (Malda town, India) and were brought to the laboratory. The plants were washed repeatedly, cut into pieces and dried under shade for two weeks. The dried plant materials were milled to form fine powder, and were processed to prepare the aqueous extract of E. fluctuans (AEE) and methanolic extract of E. fluctuans (MEE), as described earlier [6, 7]. For the preparation of MEE, $5 \mathrm{~g}$ of sample powder was soaked in $50 \mathrm{ml}$ methanol for $72 \mathrm{~h}$ with manual shaking at $2 \mathrm{~h}$ intervals, and in order to prepare AEE, $5 \mathrm{~g}$ of the powdered E. fluctuans was boiled in a conical flask containing $50 \mathrm{ml}$ double distilled water, for $30 \mathrm{~min}$, without pressure. The prepared extracts (following filtration through cheese cloth and thereafter through Whatman No. 1 filter paper): MEE and AEE were stored at $4{ }^{\circ} \mathrm{C}$, for further analysis, within next two weeks of extract preparation. The extracts were prepared afresh according to the need. The concentration of the prepared MEE and AEE was $100 \mu \mathrm{g} / \mu \mathrm{l}$.

\subsection{Phytochemical analysis}

The bioactive components, such as flavonoids, steroids, terpenoids, quinone, phenol, cardiac glycosides, anthraquinone glycosides and saponins, present in the plant extracts have been detected qualitatively, following the protocol mentioned elsewhere $[6,8]$.

The Enhydra fluctuans methanolic extract was subjected to HPLC analysis in the YL 9000 HPLC system with $\mathrm{C}_{18}$ column (5 $\mu \mathrm{m} ; 100 \AA ; 4.6 \times 250 \mathrm{~mm}$ ), as described earlier [7, 8], using the mobile phase that was composed of water and acetonitrile (1:4 ratio), and the detection of the eluting components was done at $254 \mathrm{~nm}$, at $35^{\circ} \mathrm{C}$.

\subsection{Antibacterial activity of plant extracts}

The antibacterial activity of the prepared extracts (AEE and MEE) was determined by agar-well diffusion method [7, 8], in order to measure the zone diameter of the inhibition (ZDI), as well as by agar dilution method [9], in order to assess the minimum inhibitory concentration (MIC), the details of which are described elsewhere. The agar-well diffusion utilized three different concentrations: $2 \mathrm{mg} /$ well, $5 \mathrm{mg} /$ well, $7.5 \mathrm{mg} /$ well, of AEE and MEE, while the extract concentrations ranged $1.3-10 \mathrm{mg} / \mathrm{ml}$ in agar dilution method, wherein the results were interpreted as described elsewhere [9].

\subsection{Combined antibacterial activity of plant extract and antibiotics}

The antibacterial activity of plant extract, MEE ( $5 \mathrm{mg} /$ disc) combined with antibiotics: CX, PI and NA (for P. aeruginosa), CF, AM and NA (for A. baumannii), CX, PI and CF (for B. cereus) and CX, CF and AM (for L. monocytogenes), as selected on the basis of their antibiotic susceptibility, was determined following the protocol explained elsewhere. The GII (growth inhibitory index) values calculated were interpreted following the criteria published elsewhere [10, 11], in order to express the nature of the interaction (synergy, additive, or antagonism) between antibiotics and plant extract, MEE. 


\section{Results and discussion}

The antibacterial activities of AEE and MEE, in terms of ZDIs, against gram-positive and gram-negative test bacteria have been represented in Table 1.

Table 1 Antibacterial activity of aqueous extract of $E$. fluctuans (AEE) and methanolic extract of E. fluctuans (MEE)

\begin{tabular}{lllllll}
\hline Bacterial strain & \multicolumn{3}{l}{ ZDI (mm) of AEE (mg/well) } & \multicolumn{3}{l}{ ZDI (mm) of MEE (mg/well) } \\
\hline & 2.0 & 5.0 & 7.5 & 2.0 & 5.0 & 7.5 \\
A. baumannii & 17 & 18 & 21 & 16 & 17 & 20 \\
P. aeruginosa & 6 & 6 & 6 & 13 & 14 & 18 \\
E. coli ATCC 25922 & 13 & 15 & 19 & 12 & 18 & 20 \\
B. cereus & 13 & 15 & 17 & 15 & 16 & 18 \\
L. monocytogenes & 10 & 11 & 12 & 13 & 17 & 21 \\
L. monocytogenes MTCC 657 & 11 & 12 & 13 & 16 & 19 & 24 \\
\hline
\end{tabular}

The AEE extracts had ZDIs of 6 - $21 \mathrm{~mm}$, and the MEE displayed ZDIs in the range from $12 \mathrm{~mm}$ to $24 \mathrm{~mm}$. As has been reported by Amin et al. [12], both the methanolic and acetonic leaf extracts ( $400 \mu \mathrm{g} / \mathrm{disc}$ ) of $E$. fluctuans showed efficacy against gram-positive (Bacillus cereus) and gram-negative (Escherichia coli) bacteria with ZDI of $10 \mathrm{~mm}$. The toluene extract of E. fluctuans had antibacterial activity against all the test bacteria: Staphylococcus aureus (ZDI: 7 - 15 mm), Escherichia coli (ZDI: $14-20 \mathrm{~mm}$ ), Klebsiella pneumoniae (ZDI: $11-18 \mathrm{~mm}$ ), while the methanolic E. fluctuans extracts showed inhibitory action against a single strain of Staphylococcus aureus (out of five strains tested), as has been demonstrated by Sarma et al. [13]. In the current study, AEE had no zone of inhibition (ZDI: 6 mm) against $P$. aeruginosa, while concentration dependent activity was seen against A. baumannii (ZDI: 17 - $21 \mathrm{~mm}$ ), B. cereus (ZDI: 13 - $17 \mathrm{~mm}$ ) and L. monocytogenes (ZDI: $10-12 \mathrm{~mm}$ ) clinical isolates, while the MEE showed antibacterial activity against all gramnegative clinical (A. baumannii and P. aeruginosa) and standard (E. coli ATCC 25922) and all gram-positive clinical (B. cereus and L. monocytogenes) and standard (L. monocytogenes MTCC 657) bacteria tested, displaying ZDIs 12 - 20 mm and $13-24 \mathrm{~mm}$, respectively. The concentration dependent antibacterial activity of plant extract against gram-negative (Pseudomonas aeruginosa, Salmonella typhi, Escherichia coli, Proteus vulgaris, Klebsiella pneumoniae) as well as grampositive (Bacillus cereus, Enterococcus faecalis and Staphylococcus aureus) bacteria, has been reported earlier [14], and that the instant study results, as represented in (Table 1), are in consonance with the findings as reported by Sivaranjani et al. [14].

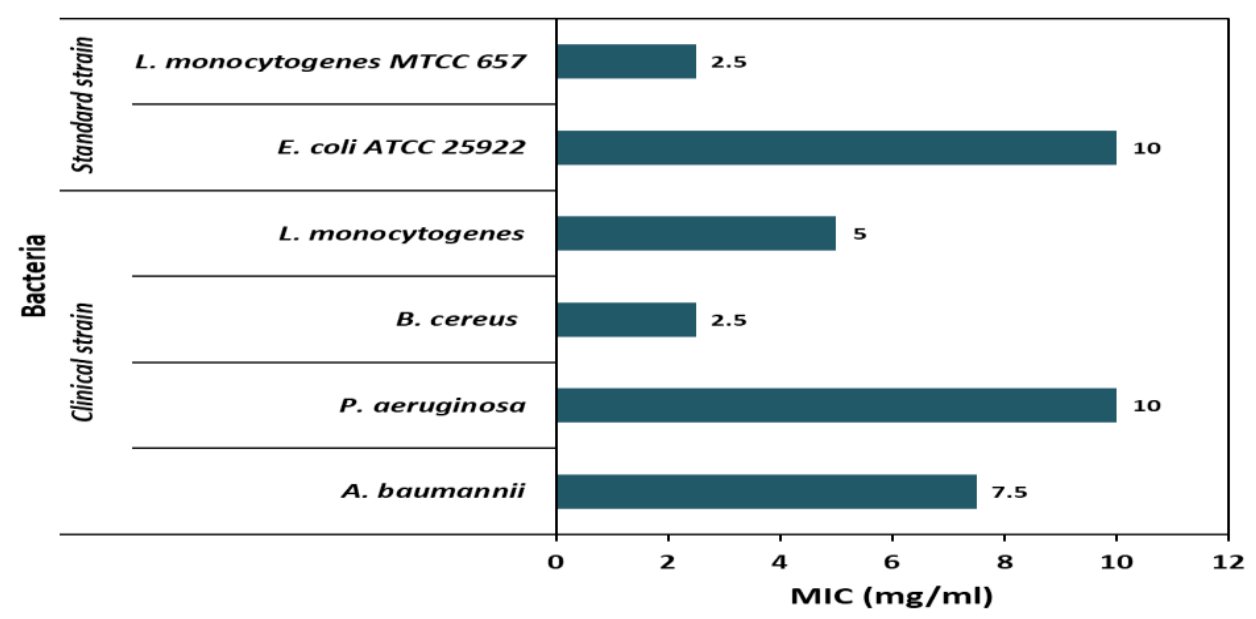

Figure 1 MIC (minimum inhibitory concentration) values of methanolic extract of $E$. fluctuans

The MICs of MEE against the test bacterial strains are represented in Figure 1. The MEE had MICs of $2.5-5 \mathrm{mg} / \mathrm{ml}$ against gram-positive clinical bacteria, while the values ranged $7.5-10 \mathrm{mg} / \mathrm{ml}$ for gram-negative clinical bacteria; lower 
MIC (2.5 mg/ml) was seen for L. monocytogenes MTCC 657 strain compared to the MIC of $10 \mathrm{mg} / \mathrm{ml}$, as displayed against ATCC E. coli 25922 (Figure 1); the AEE had MICs $>10 \mathrm{mg} / \mathrm{ml}$ for all the test bacteria (not shown in the figure). As per the demonstration of Sarma et al. [13], the E. fluctuans toluene extract MICs for the test clinical bacterial isolates ranged $25-50 \mathrm{mg} / \mathrm{ml}$, while the MICs of methanolic E. fluctuans extract was $100 \mathrm{mg} / \mathrm{ml}$, for both the gram-negative and grampositive bacteria. Thus, in the current study, agar-well (in terms of ZDIs) as well as agar dilution (in terms of MICs) techniques achieved excellent antibacterial activity against gram-positive and gram-negative pathogenic bacteria.

Table 2 Antibiotic-plant extract combined antibacterial activity test results

\begin{tabular}{|c|c|c|c|c|c|c|c|c|c|c|c|}
\hline \multirow[t]{3}{*}{ Bacterial strains } & \multicolumn{11}{|c|}{ ZDI (mm) } \\
\hline & \multirow{2}{*}{$\begin{array}{l}\text { ME } \\
\text { E }\end{array}$} & \multicolumn{5}{|c|}{ Antibiotic } & \multicolumn{5}{|c|}{ Antibiotic-MEE combination } \\
\hline & & $\mathrm{CX}$ & PI & $\mathrm{AM}$ & NA & $\mathrm{CF}$ & CX-MEE & PI-MEE & AM-MEE & NA-MEE & CF-MEE \\
\hline A. baumannii & 17 & 20 & 21 & 6 & 6 & 18 & ND & ND & 22 & 25 & 25 \\
\hline P. aeruginosa & 14 & 6 & 6 & 20 & 12 & 20 & 16 & 16 & ND & 16 & ND \\
\hline B. cereus & 16 & 15 & 23 & 18 & 21 & 15 & 21 & 29 & ND & ND & 23 \\
\hline L. monocytogenes & 17 & 18 & 24 & 13 & 23 & 12 & 24 & ND & 25 & ND & 25 \\
\hline
\end{tabular}

AM: ampicillin, CF: cefotaxime, CX: cloxacillin, NA: nalidixic acid, PI: piperacillin, MEE: methanolic extract of E. fluctuans, ND: not done, ZDI: zone diameter of the inhibition.

Earlier the synergistic interactions between antibiotics and indigenous plant extracts have been reported against clinical isolates of gram-positive and gram-negative bacteria [10,11]. Herein, the test has been performed on the combination effect between antibiotics (as selected on the basis of the test bacterial susceptibility to antibiotics) and MEE (5 mg/ml) against both gram-positive and gram-negative bacteria, and the results, in terms of ZDIs, are represented in Table 2. The toluene extract of E. fluctuans, when combined with oxacillin had increment of ZDI (from 6 $\mathrm{mm}$ to $10-12 \mathrm{~mm}$ ), against gram-positive bacteria (Staphylococcus aureus) compared to the oxacillin alone, whereas the extract, in combination with ceftazidime, had increased ZDIs, from 6 - $7 \mathrm{~mm}$ (ceftazidime alone) to 12 - $15 \mathrm{~mm}$ (from the action ceftazidime-E. fluctuans extract combination), when tested against gram-negative bacteria [13]. The GIIs from the combined action between MEE and antibiotics are depicted in Table 3. As per the criteria mentioned earlier [10, 11], the GIIs, which ranged 0.59 - 1.08, from the antibiotic-MEE combined action, demonstrated synergism against the bacteria tested in the current study.

Table 3 The nature of interaction and GII values from combined antibacterial activity of antibiotics and plant extract

\begin{tabular}{|c|c|c|c|}
\hline Bacterial strains & Combined agents & GII & Interaction \\
\hline \multirow[t]{3}{*}{ P. aeruginosa } & CX-MEE & 0.80 & Synergistic \\
\hline & PI-MEE & 0.80 & Synergistic \\
\hline & NA-MEE & 0.60 & Synergistic \\
\hline \multirow[t]{3}{*}{ A. baumannii } & CF-MEE & 1.08 & Synergistic \\
\hline & AM-MEE & 0.95 & Synergistic \\
\hline & NA-MEE & 0.71 & Synergistic \\
\hline \multirow[t]{3}{*}{ B. cereus } & CX-MEE & 0.67 & Synergistic \\
\hline & PI-MEE & 0.74 & Synergistic \\
\hline & CF-MEE & 0.74 & Synergistic \\
\hline \multirow[t]{3}{*}{ L. monocytogenes } & CX-MEE & 0.68 & Synergistic \\
\hline & CF-MEE & 0.83 & Synergistic \\
\hline & AM-MEE & 0.86 & Synergistic \\
\hline
\end{tabular}

The formerly published scientific reports showed the presence, in the plant extracts studied, of an array of bioactive phytochemicals accounting the antibacterial activity against antibiotic resistant pathogenic bacteria [7, 15]. In the instant study, both the extracts (AEE and MEE) have been tested qualitatively positive for the presence of flavonoids, 
glycosides, steroids, terpenoids, phenols, quinone and saponins, while cardiac glycoside was detected only in the AEE. Akhe et al. [5] detected different phytochemicals: flavonoids, tannins, glycoside, steroid, alkaloid and saponin, in ethanol extract of E. fluctuans by qualitative analysis. Kuri et al. [16] showed the presence of flavonoids, saponins, diterpenes, triterpenes and phenols, in methanolic extracts of $E$. fluctuans, and, similar to the instant study, cardiac glycoside was not detected. Haoya et al. [17] reported the presence of steroids, saponins, flavonoids and diterpenes, both in methanolic and ethanolic extracts of E. fluctuans, displaying antibacterial activity against E. coli (ZDI: $12 \mathrm{~mm}$ at $400 \mu \mathrm{g} / \mathrm{disc}$ ) with the ethanolic extract. As per the report of Sarma et al. [13], the E. fluctuans toluene and methanol extracts contained bioactive compounds (saponins, tannins, alkaloids, flavonoids, anthraquinones, cardiac glycosides and steroids) showing a broad spectrum of antibacterial activity. Yadava and Singh [18] isolated a novel bioactive component (from the methanolic extract of the leaves of Enhydra fluctuans): isoflavone glycoside, which has been found to exhibit growth inhibitory activity against gram-positive (Staphylococcus aureus and Bacillus cougulans) and gram-negative bacteria Escherichia coli. The preliminary phytochemical screening, as has been demonstrated by Kamal et al. [3], of E. fluctuans substantiated the existence of alkaloids, saponins, tannins and flavonoids, displaying antibacterial activity against Escherichia coli, Pseudomonas aeruginosa, B. megaterium and S. aureus [3].

Abegunde et al. [19] demonstrated phytochemical analysis of aqueous as well as ethanolic extracts of different plants displaying antibacterial activity. Herein, the phyto-components detected in MEE and AEE credibly played role in exhibiting broad spectrum antibacterial activity. The HPLC chromatogram showed the presence of 14 detectable compounds, within the retention time of 1.53 - $5.69 \mathrm{~min}$, in MEE (Figure 2). As reported earlier [7, 8], the HPLC has been found as the essential means of identifying, quantifying, and purifying of bioactive phytochemicals in different indigenous plant extracts. According to Akhe et al. [5], the HPLC profiles had four ployphenolic compounds: catechin hydrate, vanillic acid, $p$-coumaric acid and ellagic acid in the E. fluctuans crude extract, whereas catechin hydrate, $p$ coumaric acid, ellagic acid, caffeic acid and kaempferol were identified in the aqueous ethanol fraction, and Gallic acid and kaempferol were detected in the n-hexane fraction. An array of the E. fluctuans bioactive components, alone and in combination with antibiotics, plausibly played role in displaying antibacterial activity against gram-positive and gramnegative pathogenic bacteria.

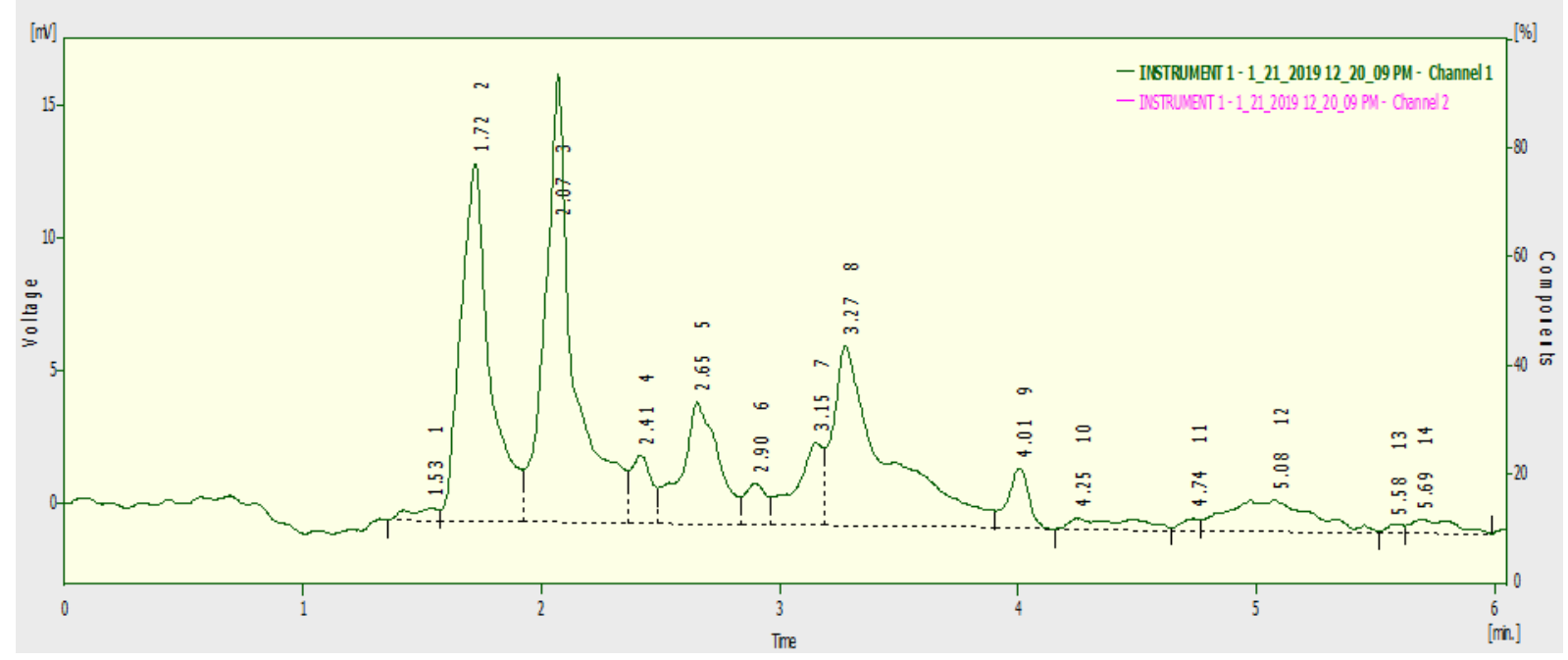

Figure 2 The HPLC chromatogram of methanolic extract of E. fluctuans

\section{Conclusion}

The broad antibacterial spectrum against gram-negative (Acinetobacter baumannii and Pseudomonas aeruginosa) and gram-positive (Bacillus cereus and Listeria monocytogenes) pathogenic bacteria of E. fluctuans possessing bioactive components might open a new vista in finding the essence of the agent(s) responsible, and thus to prepare the nonantibiotic treatment protocol in tackling the illnesses of bacterial infections to humans. The antibacterial synergy of $E$. fluctuans extract combined with antibiotics, and further pharmacokinetics assay, will aid the process in therapeutic dose determination. 


\section{Compliance with ethical standards}

\section{Acknowledgments}

The laboratory members (Laboratory of Microbiology and Experimental Medicine) are acknowledged for their help during conducting this project.

\section{Disclosure of conflict of interest}

There is no conflict of interest in publishing the present data of the study.

\section{References}

[1] Mandal S. (2015). Can over-the-counter antibiotics coerce people for self-medication with antibiotics? Asian Pac J Trop Med, 5(1), S184-S186.

[2] WHO. (2002). WHO Traditional medicine strategy: 2002-2005, World Health Organization; Geneva.

[3] Kamal S, Rony SR, Sharmin S, Laboni FR and Sohrab MH. (2019). Phytochemical and pharmacological potential of Enhydra fluctuans available in Bangladesh. J Pharma Res Inter, 29(4), 1-11.

[4] Ali MR, Billah MM, Hassan MM, Dewan RMH and AL-Emran M. (2013). Enhydra fluctuens Lour: a review. Res J Pharma Technol, 6, 927-929.

[5] Akhe FK, Khatun MM, Ray S, Arafat ST, Uddin, SJ, Hossain H, Siddiqui MN and Sarower MG. (2019). Profiling of bioactive compounds in water cress (Enhydra fluctuans Lour) by high performance liquid chromatography. Pharmaco Online, 1, 65-75.

[6] Sircar B and Mandal S. (2017). Screening of Elaeocarpus floribundus fruit extracts for bioactive phytocomponents and antibacterial activity against food-borne bacteria. Int J Res Med Sc, 5(8), 3665-3671.

[7] Das MK, Mandal M and Mandal S. (2017). Broad antibacterial spectrum and high performance liquid chromatography profiles of Ocimum sanctum leaf extract. Acta Scientific Pharma Sc, 1(6), 2-7.

[8] Sircar B, Mandal M, Mondal MA and Mandal S. (2017). High performance liquid chromatography analysis and anti-methicillin resistant Staphylococcus aureus activity of olive fruit ethanolic extract. Int Res J Pharm, 8(7), 126-130.

[9] Mandal S, Mandal M and Pal NK. (2007). Antibacterial potential of Azadirachta indica seed and Bacopa monniera leaf extracts against multidrug resistant Salmonella enterica serovar Typhi isolates. Arch Med Sc, 3, 14-18.

[10] Mandal S, Mandal MD and Pal NK. (2010). Synergistic anti-Staphylococcus aureus activity of amoxicillin in combination with Emblica officinalis and Nymphae odorata extracts. Asian Pac J Trop Med, 3(9), 711-714.

[11] Mandal S, Mandal MD and Pal NK. (2012). Enhancing chloramphenicol and trimethoprim in vitro activity by Ocimum sanctum Linn. (Lamiaceae) leaf extract against Salmonella enterica serovar Typhi. Asian Pac J Trop Med, 5, 220-224.

[12] Amin MR, Mondol R, Habib MR and Hossain MT. (2012). Antimicrobial and cytotoxic activity of three bitter plants-Enhydra fluctuans, Andrographis Peniculata and Clerodendrum Viscosum. Adv Pharm Bull, 2(2), $207-211$.

[13] Sarma U, Borah VV, Saikia KK and Hazarika NK. (2016). Screening of Enhydra fluctuans for phytochemical composition and broad-spectrum antibacterial activity against clinical bacterial isolates. J Herbs Spices Med Plants, 22(4), 300-308.

[14] Sivaranjani D, Saranraj P, Manigandan M and Amala K. (2019). Antimicrobial activity of Plectranthus amboinicus solvent extracts against human pathogenic bacteria and fungi. J Drug Dev Therapeut, 9(3), 36-39.

[15] Soni A and Dahiya P. (2015). Screening of phytochemicals and antimicrobial potential of extracts of Vetiver zizanoides and Phragmites karka against clinical isolates. Int J Appl Pharmaceut, 7(1), 22-24.

[16] Kuri S, Billah MM, Rana SMM, Naim Z, Islam MMH, Ramjan M and Banik R. (2011). Phytochemical and in vitro biological investigations of methanolic extracts of Enhydra fluctuans Lour. Asian Pac J Trop Med, 4(9), 735-738.

[17] Haoya NA, Islam MS, Sultana S, Mahia SS and Sukorno FS. (2018). Phytochemical screening and evaluation of antioxidant, antibacterial and cytotoxicity activities of methanolic and ethanolic Extracts of Enhydra fluctuans Lour (Helencha) (Family: Asteraceae) stems and leaves. Int J Plant Soil Sci, 23(6), 1-14. 
GSC Biological and Pharmaceutical Sciences, 2020, 12(02), 136-142

[18] Yadava RN and Singh SK. (2007). Novel bioactive constituents from Enhydra fluctuans lour. Nat Prod Res, 21(6), 481-486.

[19] Abegunde SM, Akinyele SA and Ayodele-Oduola RO. (2020). Chemical analysis and antibacterial activities of Calotropis procera and Clusia rosea leaves extracts. GSC Biological and Pharmaceutical Sciences, 12(1), 25-30. 